\title{
Epidemiology and Clinical Presentation in Esophageal Cancer
}

Satvinder S. Mudan and Jin-Yong Kang

\section{Introduction}

The esophagus begins at the level of the cricopharyngeus and traverses the length of the neck to pass through the mediastinum. It then pierces the right crus of the diaphragm and after a short abdominal component joins the stomach at the cardia. For descriptive purposes the esophagus is referred to as cervical $(\sim 6 \mathrm{~cm})$, thoracic $(\sim 25 \mathrm{~cm})$, and abdominal $(\sim 4 \mathrm{~cm})$. Surgeons often refer to the esophagus in divisions of one-third, upper, middle, and distal, as this better relates to the operative options in esophagectomy.

Although not as common as cancer of other sites such as prostate, breast, and colorectum, esophageal cancer has a high lethality rate, the incidence being close to the cancer-specific mortality. Thus, in the USA in 2006, esophageal carcinoma was the 15th commonest cancer, with an estimated 14550 cases, but it had the 8th highest mortality rate, with an estimated 13770 deaths [1].

Esophageal cancer is remarkable for its marked variation by geographical region, ethnicity, and gender. There is a greater than tenfold difference in incidence rates between countries with a low incidence, for example, the United States, and those with a high incidence such as high-risk areas in Iran and China [2]. More than 90\% of esophageal cancers are either squamous cell carcinomas (SCCs) or adenocarcinomas, with other tumor types such as melanomas, stromal tumors, lymphomas, or neuroendocrine cancers occurring only rarely in the esophagus. Most esophageal cancers occur in the lower and middle thirds, the cervical esophagus being an uncommon site of disease.

Although the presentation of SCC and adenocarcinoma of the esophagus in the patient are similar, the epidemiology, etiologoy, tumor biology, treatment strategies, and outcomes are quite different, and they are really two different diseases that occur in the same organ $[3,4]$ (Table 1.1). 
Cambridge University Press

978-0-521-88285-9 - Carcinoma of the Esophagus

Edited by Sheila C. Rankin

Excerpt

More information

Table 1.1 Squamous cell carcinoma and adenocarcinoma of the esophagus: epidemiology, etiology, and symptoms

\begin{tabular}{|c|c|c|}
\hline & Squamous cell carcinoma & Adenocarcinoma \\
\hline Age & $60-70$ years, median 62.6 years & $50-60$ years, median 53.4 years \\
\hline Sex & $\begin{array}{l}\text { Male dominant, lower socioeconomic } \\
\text { group }\end{array}$ & $\begin{array}{l}\text { Male dominant, middle or upper } \\
\text { socioeconomic group, } 52 \% \text { are } \\
\text { university graduates }\end{array}$ \\
\hline Associations & $\begin{array}{l}\text { Head and neck cancer, smoking, alcohol } \\
\text { excess and liver dysfunction, radiation } \\
\text { exposure, achalasia, poor nutritional } \\
\text { status, human papillomavirus (HPV) } \\
\text { infection, Helicobacter pylori infection, } \\
\text { Plummer-Vinson syndrome, tylosis } \\
\text { palmaris, lye ingestion }\end{array}$ & $\begin{array}{l}\text { Barrett's esophagus, gastroesophageal } \\
\text { reflux disease, hiatus hernia, } \\
\text { obesity, scleroderma, family history }\end{array}$ \\
\hline Location & $\begin{array}{l}\text { Mostly midesophagus ( } 75 \% \text { at level } \\
\text { of tracheal bifurcation) and with a } \\
\text { prominently linear growth pattern } \\
\text { and wider nodal spread }\end{array}$ & $\begin{array}{l}\text { Almost always distal one-third of } \\
\text { esophagus ( } 94 \% \text { entirely subcarinal) } \\
\text { and radial growth pattern with } \\
\text { early local nodal dissemination }\end{array}$ \\
\hline $\begin{array}{l}\text { Symptoms } \\
\text { and wider } \\
\text { nodal } \\
\text { spread }\end{array}$ & $\begin{array}{l}\text { Progressive dysphagia, odynophagia, } \\
\text { halitosis, unintentional weight loss, } \\
\text { chest pain }\end{array}$ & $\begin{array}{l}\text { Progressive dysphagia, odynophagia, } \\
\text { halitosis, unintentional weight loss, } \\
\text { chest pain }\end{array}$ \\
\hline
\end{tabular}

\section{Epidemiology}

The epidemiology of esophageal cancer in the Western world has changed dramatically over the last two decades. Up until the 1970s most esophageal cancers were of the squamous cell type, affecting mostly elderly men drawn from the poorer social classes and influenced by smoking and alcohol consumption. Since then there has been a dramatic increase in the incidence of adenocarcinoma, which tends to affect more affluent white men, often in their most productive years of life [2].

\section{Squamous cell carcinoma}

SCC of the esophagus remains in the top ten of cancers globally and represents a major healthcare problem. The marked geographical variation in incidence suggests that environmental factors are paramount in its causation. High-incidence 
regions of the world such as Southern and Eastern Africa, and a central Asian belt passing from Turkey through countries such as Iraq, Iran, and Kazakhstan and on to Northern China, are marked out by poverty and other poverty-related illnesses. The incidence in high-risk provinces can reach up to 100/10 000 per year compared to $5-10 / 10000$ per year in Western countries [2]. In the USA, SCC is more common among black people than among white people, but incidence rates have fallen by half across both groups between 1970 and 2000, with incidence rates of approximately $2 / 100000$ for white males and 10/100 000 for black people in 2000 $[1,2,5]$. These figures are probably related to increasing levels of wealth and education and reduction in exposure to causative agents.

The male: female ratio is 3:1 except in high-incidence areas where the distribution is more equal and reflects an equal exposure to risk factors [6]. Regional, socioeconomic, and racial variation within a country is demonstrated by a higher incidence of SCC in low income and low socioeconomic groups $[5,7,8]$.

\section{Adenocarcinoma}

The last 30 years have seen a dramatic fall in the incidence of noncardia gastric cancer and, as mentioned earlier, a decline or stabilization in the incidence of SCC of the esophagus in Western countries $[9,10,11,12,13]$. Over the same period the age-standardized incidence of adenocarcinoma of the lower esophagus, previously a rare disease with incidence $<1 / 100000$, has risen more rapidly than any other malignancy in the Western world. Since the mid 1990s its incidence has exceeded that for SCC $[14,15,16]$. The rise in incidence is most marked in the white male population, reaching about 5/100 000 for the white males in North America and 8-12/100 000 for white males in the highest incidence countries of Australia and the UK $[7,13,17,18,19,20,21,22]$. This represents an increase of about $400-800 \%$ from the 1970s and is about four times greater than the incidence for black males in the United States. The trend is similar for other North European countries $[10,23,24,25]$. Not only is the incidence higher in white males, but the annual increase in incidence, $\sim 10 \%$ per year, is higher than for other racial groups and for white females, leading to an increasing sex and racial ratio [17,26,27]. The demographic distribution shows an age peak at 50-60 years and a male: female ratio between 2:1 and 12:1 [23]. Although it is possible that improved anatomic classification and histological verification might account for some of the time trends noted, the rapid changes point to a newly acquired etiological risk factor $[10,13,14]$. 


\section{Etiology}

\section{Squamous cell carcinoma}

Many of the environmental factors associated with a high incidence of SCC of the esophagus relate to poor socioeconomic circumstances. A diet rich in preserved and pickled foods and low in fresh fruit and vegetables, vitamin and mineral deficiencies, and a thermal effect of hot food and beverages have all been implicated. Alcohol intake and smoking are also strongly associated with an increased risk of SCC of the esophagus $[28,29,30,31]$. The risk is thought to be dose related and the genetic changes brought about by chronic exposure to causative agents lead to a progression through epithelial dysplasia and carcinoma in situ to invasive cancer [32]. After several years of cessation of exposure to irritant factors, such as smoking and alcohol, risk is substantially reduced [33]. Conditions such as caustic ingestion and achalasia of the cardia, which are associated with chronic mucosal inflammation, also predispose to SCC of the esophagus.

\section{Adenocarcinoma}

The recent and rapid escalation in incidence of esophageal adenocarcinoma would seem to suggest a mostly environmental rather than genetic effect. While a number of factors including race, obesity, use of esophageal sphincter-relaxing drugs, smoking, and alcohol consumption have all been incriminated as possible etiological factors in esophageal adenocarcinoma [34,35,36,37,38], many cohort studies have pointed strongly to gastroesophageal reflux and Barrett's disease (Barrett's esophagus) as a causative factor $[39,40]$.

There is a strong dose-response relationship between previous gastroesophageal reflux symptoms and esophageal adenocarcinoma, but the relationship to cardia cancer is weaker [40]. Wu et al. demonstrated a threefold increase in esophageal cancer and a doubling in cardia cancer with reflux symptoms [41]. The relationship between adenocarcinoma of the lower esophagus and adenocarcinoma of the cardia is less clear. Siewert et al. have separated adenocarcinoma occurring at or near the gastroesophageal junction into three groups depending on the anatomic relation to the gastroesophageal junction. Type 1 tumors represent cancers of the lower esophagus, mostly arising in Barrett's esophagus. Type 2 and 3 tumors represent true cardia and proximal gastric cancers, respectively [42], and while their incidence has risen in recent decades, the changes are not as marked as for true lower esophageal adenocarcinoma that are associated with Barrett's esophagus, Type I. The clinical 
behavior and treatment of type 2 and 3 tumors are more like those of gastric carcinoma $[43,44]$.

Gastroesophageal reflux leads to columnar cell metaplasia in the distal esophageal epithelium, a condition known as Barrett's esophagus. This increases the risk of developing esophageal adenocarcinoma 30 - to 60 -fold. The squamous cell epithelium of the normal esophagus is replaced with a mature columnar-type epithelium, with Barrett's mucosa being derived from pleuripotential cells in the basal layer of the esophageal epithelium $[45,46,47]$. The presence of goblet and pregoblet cells is a requisite for intestinal metaplasia, which is associated with the increased risk of malignant transformation. The probable driver toward metaplasia is that the columnar epithelium is more tolerant of refluxate and the progression to columnar metaplasia is a function of the refluxate content and periodicity [34]. Metaplasia of fundic- or cardiac-type gastric mucosa not involving the presence of goblet cells is thought to carry a lower risk of malignant transformation. Most cases of distal esophageal adenocarcinomas (90\%) are thought to arise in the setting of Barrett's esophagus [48]. In other words, the risk of malignant transformation is greatly elevated in patients with Barrett's esophagus and much less elevated in patients with reflux esophagitis or nonerosive gastroesophageal reflux without Barrett's esophagus. Solaymani-Dodaran et al. reported relative risks for developing esophageal adenocarcinoma of 29.8 for Barrett's esophagus, 4.5 for reflux esophagitis, and 3.1 for gastroesophageal reflux without Barrett's esophagus or reflux esophagitis [39]. A patient with Barrett's esophagus has a 5\% lifetime risk of developing esophageal adenocarcinoma. The risk of transformation from benign intestinal epithelium in Barrett's esophagus to dysplasia and then adenocarcinoma is related to the length of Barrett's epithelium lining the esophagus, duration of reflux disease, and presence of a hiatus hernia [49,50,51]. The risk of transformation may be mitigated by antireflux surgery, but the evidence is not strong enough to recommend this as a strategy for cancer prevention. Molecular markers of high risk are recognized but do not as yet form part of routine practice $[52,53,54,55]$.

Dysplasia is classified as low or high grade and is characterized by the degree of hyperchromasia, nuclear: cytoplasm ratio, and glandular atypia. High-grade dysplasia is considered as indicative of at least an intraepithelial malignancy. About one-third of patients with high-grade dysplasia at biopsy will have invasive disease evident on a resection specimen. In population terms Barrett's esophagus is a common condition, occurring in $0.45-2.2 \%$ of all patients undergoing upper GI endoscopy, about $12 \%$ of patients undergoing endoscopy for reflux symptoms, and about $0.3 \%$ in unselected autopsy series [56]. While excess exposure to acid is 
demonstrable in most patients with Barrett's esophagus, progression to dysplasia is more likely in patients with alkaline or bile-containing duodenogastric reflux rather than those with pure acid reflux [57,58].

Several other potential causative factors have been evaluated. The incidence of esophageal adenocarcinoma has increased since the introduction of powerful acid suppressants such as histamine-2 receptor antagonists and proton pump inhibitors, but the lead time for carcinogenesis probably precludes these agents as etiological agents and the association is likely to reflect the use of these agents to treat symptoms of reflux in patients already at increased risk of developing esophageal adenocarcinoma. Drugs that reduce the lower esophageal sphincter tone, e.g., anticholingergics, nitroglycerin, beta-adrenergic agonists, aminophylline, and benzodiazepines, have all been implicated through increasing the potential for reflux [36]. Reduction in intragastric acidity through gastric mucosal atrophy-induced hypochlorhydria from Helicobacter pylori infection may be another factor in the promotion of distal esophageal SCC, while its carcinogenic effect in noncardia gastric cancer is well recognized. By contrast, Helicobacter pylori infection, especially of the cagA $\mathrm{A}^{+}$strain, may have a protective effect against esophageal adenocarcinoma $[59,60]$. The role of diet is controversial, and while there appears to be an association with noncardia gastric cancer, the link to esophageal cancer is not so clear $[61,62,63,64]$. The relationship to smoking is less clear than that for SCC. Increased abdominal pressure brought about by central obesity, sedentary posture, and tight belts has also been implicated [37,65], although a high body mass index appears to be an independent risk factor for adenocarcinoma but not SCC [38].

Familial clustering has been demonstrated in Barrett's esophagus and adenocarcinoma of the esophagus, but no "Barrett gene" has been identified, and it is not clear whether the familial tendency represents a genetic predisposition or merely the effect of similar lifestyle factors among family members [66].

The carcinogenic pathway from Barrett's mucosa involves a multistep alteration in the genotype, loss of regulatory function, induction of proinflammatory enzymes such as cyclooxygenase-2, and angiogenesis. Consequently, chemoprevention and treatment through the use of therapies directed at specific molecular targets has been postulated [67].

\section{Clinical presentation}

The majority of symptomatic patients turn out to have advanced disease. Presenting symptoms are similar for SCC and adenocarcinoma. The most common are 
dysphagia and odynophagia (i.e., pain on swallowing). The pliability of the esophagus is such that dysphagia occurs when the lumen is obstructed by about $75 \%$ of the circumference, although a small tumor may cause a tight stenosis through intense fibrosis. Chronic cough secondary to laryngopharyngeal reflux may be an early marker of malignant transformation in Barrett's esophagus [68]. Hoarseness or Horner's syndrome usually implies invasion of the recurrent laryngeal nerve or cervical ganglia, and such patients are almost always inoperable. Cervical or supraclavicular lymphadenopathy is indicative of distant spread and indicates inoperability in adenocarcinoma. It is present in about one-third of SCCs, and resection with curative intent might still be considered in this disease with radical three-field node dissection, in particular for mid- or upper-third tumors [68].

\section{Prognosis}

While some rare esophageal tumors such as lipomas or smooth muscle tumors have a good outlook, the prognosis for SCC and adenocarcinoma of the esophagus is poor with an overall tumor-specific lethality rate of $\sim 0.95$ [69]. Survival appears comparable across age groups, but females appear to have better outcomes. For patients undergoing operations with curative intent, the 5-year survival ranges from 5 to $20 \%$. Large tumors, nodal involvement, and extracapsular nodal spread are all strong prognostic factors for poor outcome [70]. Progression of nodal disease to subdiaphragmatic sites is generally considered to carry the same prognostic significance as distant metastases, although long-term survival with resection of celiac nodes is possible. It is likely that micrometastases in lymph nodes and sites such as bone marrow behave in a way different from clinically obvious disease.

Whether the type of operation performed affects outcome is uncertain. Tumor location in the upper esophagus predicates for a poor operative risk. Since most SCCs are either mid or upper esophageal cancers and other comorbidities such as age, chronic respiratory disease, liver disease, and poor nutrition are common, the immediate results of surgery are consistently worse for SCC than for adenocarcinoma $[4,71,72]$. Resections with microscopic positive surgical margins consistently perform worse than those with negative margins.

Cancer-specific outcomes have improved [73] in the last two decades through reduced surgical morbidity and mortality brought about by improvement in the perioperative care, multidisciplinary collaboration, and the use of multimodal therapies [74]. Although no survival advantage has been consistently demonstrated by adjuvant chemotherapy in resected esophageal cancer and trials of neoadjuvant 
Cambridge University Press

978-0-521-88285-9 - Carcinoma of the Esophagus

Edited by Sheila C. Rankin

Excerpt

More information

chemotherapy or chemoradiotherapy are inconsistent, a large recently published British Medical Research Council study (ST-02 MAGIC study) demonstrated a significant tumor-specific survival advantage $[75,76,77,78]$, and a distal esophageal location and a measurable response to preoperative chemotherapy appear to identify a favorable group $[74,79,80,81]$. Strategies based on identification of high-risk individuals allowing surveillance by endoscopy or molecular markers and for those progressing to cancer-targeted therapies with newer systemic agents and pretreatment response prediction are awaited $[67,82,83,84,85]$.

\section{Conclusions}

The epidemiology of esophageal cancer is rapidly changing. In Western countries, adenocarcinoma of the lower esophagus has overtaken the previously more prevalent SCC. The divergent etiology and tumor behavior between the two diseases require different prevention and treatment strategies. Until its etiology becomes better understood, the continued rise in incidence of esophageal adenocarcinoma presents a significant healthcare problem in Western countries. Better identification of those at risk, e.g., individuals with Barrett's esophagus, might allow more effective screening policies. At present, surgery, when possible, represents the only potentially curative modality, but results remain poor and we await improvements in outcome through incorporation of therapies directed at novel cellular and molecular targets.

\section{REFERENCES}

1. A. Jemal, R. Siegel, E. Ward, et al. Cancer statistics, 2006. CA Cancer J Clin, 56 (2006), 106-30.

2. R. Holmes and T. L. Vaughan. Epidemiology and pathogenesis of esophageal cancer. Semin Radiat Oncol, 17 (2007), 2-9.

3. C. Mariette, L. Finzi, G. Piessen, et al. Esophageal carcinoma: prognostic differences between squamous cell carcinoma and adenocarcinoma. World J Surg, 29 (2005), 39-45.

4. J. R. Siewert and K. Ott. Are squamous and adenocarcinomas of the esophagus the same disease? Semin Radiat Oncol, 17 (2007), 38-44.

5. L. M. Brown, R. Hoover, D. Silverman, et al. Excess incidence of squamous cell esophageal cancer among US black men: role of social class and other risk factors. Am J Epidemiol, 153 (2001), 114-22.

6. H. R. Wabinga, D. M. Parkin, F. Wabwire-Mangen, and S. Nambooze. Trends in cancer incidence in Kyadondo County, Uganda, 1960-1997. Br J Cancer, 82 (2000), 1585-92. 
Cambridge University Press

978-0-521-88285-9 - Carcinoma of the Esophagus

Edited by Sheila C. Rankin

Excerpt

More information

7. A. Kubo and D. A. Corley. Marked regional variation in adenocarcinomas of the esophagus and the gastric cardia in the United States. Cancer, 95 (2002), 2096-102.

8. X. Wu, V.W. Chen, B. Ruiz, et al. Incidence of esophageal and gastric carcinomas among American Asians/Pacific Islanders, whites, and blacks: subsite and histology differences. Cancer, 106 (2006), 683-92.

9. S. Keeney and T.L. Bauer. Epidemiology of adenocarcinoma of the esophagogastric junction. Surg Oncol Clin N Am, 15 (2006), 687-96.

10. A. P. Vizcaino, V. Moreno, R. Lambert, et al. Time trends incidence of both major histologic types of esophageal carcinomas in selected countries, 1973-1995. Int J Cancer, 99 (2002), 860-8.

11. M. Pera. Trends in incidence and prevalence of specialized intestinal metaplasia, Barrett's esophagus, and adenocarcinoma of the gastroesophageal junction. World J Surg, 27 (2003), 999-1008.

12. M. Pera, C. Manterola, O. Vidal, and L. Grande. Epidemiology of esophageal adenocarcinoma. J Surg Oncol, 92 (2005), 151-9 (Review).

13. A. Newnham, M. J. Quinn, P. Babb, J. Y. Kang, and A. Majeed. Trends in the subsite and morphology of oesophageal and gastric cancer in England and Wales 1971-1998. Aliment Pharmacol Ther, 17 (2003), 665-76.

14. H. Pohl and H. G. Welch. The role of overdiagnosis and reclassification in the marked increase of esophageal adenocarcinoma incidence. J Natl Cancer Inst, 97 (2005), 142-6.

15. N. J. Shaheen. Advances in Barrett's esophagus and esophageal adenocarcinoma. Gastroenterology, 128 (2005), 1554-66 (Review).

16. J. Lagergren. Adenocarcinoma of oesophagus: what exactly is the size of the problem and who is at risk? Gut, 54:Suppl. 1 (2005), 1-5 (Review).

17. A. Kubo and D.A. Corley. Marked multi-ethnic variation of esophageal and gastric cardia carcinomas within the United States. Am J Gastroenterol, 99 (2004), 582-8.

18. E. Bollschweiller, E. Wolfgarten, C. Gutschow, et al. Demographic variations in the rising incidence of esophageal adenocarcinoma in white males. Cancer, 92 (2001), 549-55.

19. R. V. Lord, M. G. Law, R. L. Ward, et al. Rising incidence of oesophageal adenocarcinoma in men in Australia. J Gastroenterol Hepatol, 13 (1998), 356-62.

20. A. Newnham, M. J. Quinn, P. Babb, J.Y. Kang, and A. Majeed. Trends in oesophageal and gastric cancer incidence, mortality and survival in England and Wales 1971-1998/1999. Aliment Pharmacol Ther, 17 (2003), 655-64.

21. S. S. Devesa, W. J. Blot, and J. F. Fraumeni. Changing patterns in the incidence of esophageal and gastric carcinoma in the United States. Cancer, 83 (1998), 2049-53.

22. Thames Cancer Registry. Cancer in South East England 1997 (London: Thames Cancer Registry, 2000).

23. A. A. Botterweck, L. J. Schouten, A. Volovics, et al. Trends in incidence of adenocarcinoma of the oesophagus and gastric cardia in ten European countries. Int J Epidemiol, 29 (2000), 645-54. 
Cambridge University Press

978-0-521-88285-9 - Carcinoma of the Esophagus

Edited by Sheila C. Rankin

Excerpt

More information

24. B. P. Wijnhoven, M. W. Louwman, H. W. Tilanus, and J. W. Coebergh. Increased incidence of adenocarcinomas at the gastro-oesophageal junction in Dutch males since the 1990s. Eur J Gastroenterol Hepatol, 14 (2002), 115-22.

25. L. E. Hansson, P. Sparen, and O. Nyren. Increasing incidence of both major histological types of esophageal carcinomas among men in Sweden. Int J Cancer, 54 (1993), 402-7.

26. J. Powell, C. C. McConkey, E. W. Gillison, et al. Continuing rising trend in oesophageal adenocarcinoma. Int J Cancer, 102 (2002), 422-7.

27. M. Younes, D. E. Henson, A. Ertan, et al. Incidence and survival trends of esophageal carcinoma in the United States: racial and gender differences by histological type. Scand J Gastroenterol, 37 (2002), 1359-65.

28. L. S. Engel, W.H. Chow, T.L. Vaughan, et al. Population attributable risks of esophageal and gastric cancers. J Natl Cancer Inst, 95 (2003), 1404-13.

29. M. Farhadi, Z. Tahmasebi, S. Merat, et al. Human papillomavirus in squamous cell carcinoma of esophagus in a high-risk population. World J Gastroenterol, 11 (2005), 1200-3.

30. S. Bahmanyar and W. Ye. Dietary patterns and risk of squamous-cell carcinoma and adenocarcinoma of the esophagus and adenocarcinoma of the gastric cardia: a population-based casecontrol study in Sweden. Nutr Cancer, 54 (2006), 171-8.

31. H. Boeing, T. Dietrich, K. Hoffman, et al. Intake of fruits and vegetables and risk of cancer of the upper aero-digestive tract: the prospective EPIC-study. Cancer Causes Control, 17 (2006), 957-69.

32. H. Kuwano, H. Kato, T. Miyazaki, et al. Genetic alterations in esophageal cancer. Surg Today, 35 (2005), 7-18.

33. C. H. Lee, J. M. Lee, D. C. Wu, et al. Independent and combined effects of alcohol intake, tobacco smoking and betel quid chewing on the risk of esophageal cancer in Taiwan. Int J Cancer, 113 (2005), 456-63.

34. S. R. DeMeester and T.R. DeMeester. Columnar mucosa and intestinal metaplasia of the esophagus: fifty years of controversy. Ann Surg, 231 (2000), 303-21 (Review).

35. S. R. DeMeester. Adenocarcinoma of the esophagus and cardia: a review of the disease and its treatment. Ann Surg Oncol, 13 (2006), 12-30.

36. J. Lagergren, R. Bergstrom, H. O. Adami, and O. Nyren. Association between medications that relax the lower esophageal sphincter and risk for esophageal adenocarcinoma. Ann Intern Med, 133 (2000), 165-75.

37. J. Lagergren and C. Jansson. Use of tight belts and risk of esophageal adenocarcinoma. Int J Cancer, 119 (2006), 2464-6.

38. J. Lagergren, R. Bergstrom, and O. Nyren. Association between body mass and adenocarcinoma of the esophagus and gastric cardia. Ann Intern Med, 130 (1999), 883-90.

39. M. Solaymani-Dodaran, R. F. Logan, J. West, et al. Risk of oesophageal cancer in Barrett's oesophagus and gastro-oesophageal reflux. Gut, 53 (2004), 1070-4.

40. J. Lagergren, R. Bergstrom, A. Lindgren, and O. Nyren. Symptomatic gastroesophageal reflux as a risk factor for esophageal adenocarcinoma. N Engl J Med, 340 (1999), 825-31. 